\title{
Toward narrowing the theory-practice gap: characterizing evidence from in-service biology teachers' questions asked during an academic course
}

\author{
Yael Furman Shaharabani ${ }^{1}$ and Anat Yarden $^{2^{*}}$ (D)
}

\begin{abstract}
Background: The gap between theory and teachers' practice is a barrier to education improvement. There is therefore an ongoing need to understand teachers' thinking and find new ways to meaningfully relate theory and practice in STEM education. The research explores, through teachers-as-learners' questions, the connections made by experienced high-school biology teachers between theory and practice, their practical concerns, and the contribution of a supportive course pedagogy to these connections. The research included 31 experienced high-school biology teachers that participated in a special graduate program.
\end{abstract}

Results: Applying a grounded theory approach, the analysis of the teachers' questions, asked as a part of their course assignments, yielded four categories: theory, practice, practice and theory, practice vs. theory. We found that most of the biology teachers' questions asked under a supportive pedagogical design, directed at mediating theory and practice, associated practice and theory. The teachers formed two types of connections between practice and theory in their questions. While asking questions associating practice and theory, the teachers mentioned practical aspects of their work. The types of connections between theory and practice are discussed, as well as the relevance to teacher education.

Conclusions: The opportunity to ask questions during assignments that are topic-specific and designed to combine practice and theory enabled teachers to think of both domains and try to better understand their association. The research results indicate that the questions asked by teachers-as-learners can serve a dual purpose: as a way to help teachers direct their thinking to the association between theory and practice, and as a tool to describe and understand teachers' tacit thinking. This research also emphasizes the importance of supporting STEM teachers by developing courses and professional development programs that explicitly combine educational theory and practice.

Keywords: Experienced teacher, Theory-practice connection, Instructional design, In-service teacher education, teacher's question, High-school biology

\section{Introduction}

Effective Science Technology Engineering and Mathematics (STEM) education requires teachers' continued learning and development, including implementation of research-derived knowledge to their practice. Yet, many teachers relate to educational research and theories as

\footnotetext{
* Correspondence: anat.yarden@weizmann.ac.il

${ }^{2}$ Department of Science Teaching, Weizmann Institute of Science, P.O Box 26, 76100 Rehovot, Israel

Full list of author information is available at the end of the article
}

irrelevant or far from their everyday lives, and thus the gap between theory and practice is an ongoing barrier to education improvement (De Corte, 2000; Nuthall, 2004). Teachers who valued both theory and practice during their pre-service studies were found to prefer practice once they entered into their teaching lives (Allen, 2009). Strategies such as action research or the use of case studies have been suggested to help teachers bridge the gap between theory and practice (van Driel, Beijaard, \& Verloop, 2001), but there nevertheless remains an 
ongoing need to understand teachers' thinking and find new ways to enable them to relate meaningfully theory and practice.

Questions are important markers of interest and thinking, and an intrinsic component of science and STEM education. Researchers have used questions to study various educational topics, for example, students' conceptual change (Watts, Gould, \& Alsop, 1997), teachers' professional development (Watts, Alsop, Gould, \& Walsh, 1997), and students' interest in science (BaramTsabari \& Yarden, 2009). Teachers' questions in the classroom have been extensively examined, and the importance of certain types of questions in promoting students' thinking has been acknowledged (Chin, 2007; van Zee \& Minstrell, 1997). Questions raised by teachers during their own learning process, termed here teachers-as-learners' questions, have the potential to serve as probes toward gaining a better understanding of the teachers' thinking in general, and of their perspective on practice, theory, and the connections between them in particular. In this work, we suggest that the questions that teachers ask as learners under a supporting context can serve a dual purpose, as a way to help them direct their thinking to the relations between theory and practice and as a tool to describe and understand their tacit thinking.

The research explores, through teachers-as-learners' questions, the connections made by experienced highschool biology teachers between theory and practice, their practical concerns, and the contribution of a supportive course pedagogy (discussing theory in relation to the teachers' actual work and experience) to these connections. The research included 31 experienced highschool biology teachers that participated in a special graduate program (M.Sc). In this study, we use the term theory for all types of research-based knowledge, ranging from theories and models to specific frameworks and methods. This choice reflects the way in which teachers refer to research-based knowledge, as opposed to their experience-based knowledge.

\section{Theory-practice gap}

Kennedy (1997) summarized four reasons for the wellknown lack of "usefulness of educational research" (p. 4): research is not persuasive enough; research is not relevant to practice; ideas from research are not accessible to teachers; educational systems lack the ability to change. A decade later, Broekkamp and van Hout-Wolters (2007) identified four basic and interrelated problems that contribute to the gap and demonstrate the same phenomenon: educational research yields only a few conclusive results; educational research yields only a few practical results; practitioners believe that educational research is not conclusive or practical; practitioners make little (appropriate) use of educational research. The combination of these problems seems to be holding back improvements in education, hence theoretical and practical solutions to bridge the theory-practice gap are at the heart of ongoing discussions (Korthagen, 2007).

Several potential paths to narrowing this gap hold some promise. One suggestion is to change research to better align with the needs of practice. This path calls for teachers and researchers to work together as collaborative partners in, for example, research schools that are infrastructures for connecting educational research with educational practice (Hinton \& Fischer, 2008), or during professional development programs that enable the teachers to develop research based activities (e.g., Erdas Kartal et al., 2018). Another possible solution is to better communicate research results: "good communication with practitioners which means that the relevant outcomes are translated in such a way that they become palatable, accessible, and usable for the teachers" (De Corte, 2000, p. 249).

Different means have been suggested to connect theory to practice during pre-service and in-service teachers' education (Korthagen, 2007). For example, the use of cases was suggested as a powerful tool to bridge the gap between theory and practice: in an online forum, pre-service and in-service mathematics teachers were shown to connect the theory that they had read and studied in their university methods courses with the practice that they had critically watched in a video of a real classroom (Koc, Peker, \& Osmanoglu, 2009). A different video case-based intervention at the pre-service level led to better connecting theory and practice, as revealed in pre-service teachers' growing ability to base their analysis of classroom episodes on theories (Eilam \& Poyas, 2009).

Korthagen, Loughran, and Russell (2006) suggested a seven-principle framework for teacher education to link theory and practice effectively, including an approach in which learning about teaching is enhanced through preservice teacher research. Action research, or teachers' research, is another method that may contribute to teachers' development, including better association of theory and practice (Capobianco \& Feldman, 2006; Halai, 2012; Roth, 2007). However, in many of the graduate-program courses for teachers, the performance of full-scale research is not feasible. Nevertheless, the course's pedagogical design may contribute to narrowing the theory-practice gap. Many higher education courses are still using the traditional lecture-based transformative approach (Kober, 2015), although research supports a constructivist active-learning approach. For example, a meta-analysis of 225 STEM (science, technology, engineering, and mathematics) undergraduate studies found higher student achievements under active vs. traditional 
lecturing (Freeman et al., 2014). In the courses that were the context for this study, we employed a socioconstructivist approach, engaging the teachers in collaboratively analyzing and planning instruction in relation to educational theories that had been discussed, and in reflective thinking about their instruction. Reflection is considered a major contributor to teachers' development (Bell \& Gilbert, 1996; Schon, 1983).

Here, we suggest that teachers' questions may serve as a valuable tool for understanding teachers' thinking about the connections between educational theory and their practice, and as a way to narrow the theory-practice gap.

\section{Questions as markers of interest and thinking}

Questions have been established as markers of interest and thinking (Baram-Tsabari, Sethi, Bry, \& Yarden, 2006). Questions can be viewed as expressions of the tacit subjects and issues that concern the person asking them, which are sometimes very different from what is generally expected. For instance, an analysis of questions asked by high-school biology students revealed that their interests are not aligned with the topics of the national curriculum in biology, because about half of their questions related to topics that were missing from the curriculum (Hagay \& Baram-Tsabari, 2011).

It is generally agreed that questions are strongly connected to thinking and learning (Chin \& Osborne, 2008; Dori \& Herscovitz, 1999). As Chin and Osborne (2008) stated: "Questions from students indicate that they have been thinking about the ideas presented and have been trying to link them with other things they know" (p. 2). Teachers who participate in graduate programs are learners, and as such they ask questions that reflect their thinking. In this context, it is important to emphasize the difference between self-generated questions, which are questions that are asked freely without direction, and ordered questions, which are directed to a specific topic or issue by someone other than the person asking them (Gross, 2001). Self-generated questions are internally motivated (Gross, 2001) and therefore have the potential to reveal tacit interests and concerns (Biddulph, Symington, \& Osborne, 1986). Hence, the teachers in this study were encouraged to generate questions during the course and in the different assignments.

There is a growing body of knowledge on students' questions, revealing the importance of questions to learning and as data sources for different features related to learning. For example, a review of 26 intervention studies revealed that students' level of comprehension of reading material increased after they were taught to ask questions (Rosenshine, Meisler, \& Chapman, 1996). Analysis of questions sent to an ask-a-scientist site showed that students' interest in science changes with age and gender, with girls favoring biological topics and asking less questions as they grow older (Baram-Tsabari et al., 2006). Students' question-posing capability was suggested as an alternative evaluation method of secondary science learning, and it was found that the number and complexity of the students' questions increased significantly after learning a unit that required coping with real-life problems and posing questions (Dori \& Herscovitz, 1999).

Since questions are strongly related to thinking and learning, and are a basic tool of instruction, teachers' questions in class have been investigated widely (Galloway \& Mickelson, 1973). Teachers' distinct ways of questioning have been related to helping students promote their thinking in science classes (Chin, 2007; Roth, 1996; van Zee \& Minstrell, 1997; Yip, 2004). Questions can also potentially contribute to teachers' reflection and change: students' questions served as critical incidents that helped two science teachers change their thinking and classroom practice (Watts et al., 1997). In this study, we attempt to connect two distinct areas of research: the theory-practice gap and teachers' questions. We focus on questions asked by teachers, as a window to the teachers' thinking regarding possible connections between their practice and educational theory.

\section{Methods}

The first research objective of this study was to explore the contribution of a supportive course pedagogy to the connections made between theory and practice by the participating teachers. These connections were probed using the teachers-as-learners' questions asked in the context of academic courses for biology teachers in a graduate program. The second objective was to characterize the connections made by the teachers between theory and practice and the practical aspects of their thinking during academic courses as expressed in their teachers-as-learners' questions. Specifically, the following two research questions were addressed:

1. Did-and how did-a supportive course pedagogy contribute to the formation of connections between theory and practice by the teachers?

2. What types of connections did the teachers form between theory and practice, and what are the practical aspects of these connections?

\section{Context and participants \\ The graduate program}

The Rothschild-Weizmann Program for Excellence in Science Education was established to advance the academic and professional development of secondary science and mathematics teachers in Israel. The program's goals are to empower science teachers and increase their 
motivation by providing them with unique opportunities to expand their knowledge and be involved in innovative professional activities. Realizing these goals is expected to trigger a significant increase in the level of science education in Israel. In the framework of this program, which consists of specially designed courses in Biology, Science Education, and Biology Education, experienced biology teachers are studying toward their M.Sc. degree (without thesis). The teachers participated in the program for two full days a week, and continued to teach in their schools for the rest of the week. Thus, enabling the teachers to implement new ideas and strategies they learned in the course of the program.

\section{Participants}

Thirty-one biology teachers who were participating in two courses: course A $(n=21)$ and course B $(n=10)$, were part of this study: $87 \%$ of the teachers were women; $13 \%$ were under the age of 30 , half were between the ages of 31 and 40, and the rest were over 40 years of age; $70 \%$ had over 10 years of experience in teaching secondary-school biology (grades 7-12), with the majority teaching advanced biology levels (grades 10-12).

We refer to the participants of this study as "teachers," although they are students in the described graduate program, in order to avoid misunderstandings when these teachers' students are mentioned and also to emphasize that one of the requirements for participating in the program is to be an experienced practicing teacher.

\section{The courses}

Teachers' questions were collected mainly from assignments submitted in two different biology education courses (courses A and B), and from one assignment submitted in a science education course (course $\mathrm{C}$ ).

\section{Course $A$}

The course "Learning and teaching in biology 1" was held in the first semester of the 2009-2010 academic year. The 21 biology teachers (graduate students) attended 13 meetings of $1.5 \mathrm{~h}$ each, and participated in online discussions and assignments. The course was aimed to bridge aspects of the theoretical knowledge introduced in another course ("Introduction to science education") and the biology teachers' classroom practice: i.e., knowledge about the goals of biology teaching, students' questions, means to promote students' interest in biology, and modes of learning for understanding. The course was socio-constructivist in nature, and therefore structured as workshops, during which the teachers discussed their practice in relation to theory, engaged in group work to develop theory-based teaching units, and analyzed examples of their existing teaching materials.
The teachers submitted three course assignments that focused on connecting theory and practice (Table 1). Each assignment was prepared in small groups and included a personal reflective section. They also read one paper about a topic that was not emphasized in the introductory course, and submitted a reading assignment. The personal section of all the assignments included a requirement to ask questions. The first author was the leading developer and instructor of this course.

\section{Course $B$}

The course "Introduction to biology education" was held in the first semester of the 2010-2011 academic year with ten biology teachers. The course had a similar rationale, structure, and assignment style as course A, except that this course also introduced the theoretical knowledge, since it was not accompanied by another introductory course. Theory was introduced via reading assignments and short lectures that were complemented with discussions and focused on relations to the teachers' practical experience. To maintain the socioconstructivist nature of the course, each teacher chose one reading to present and discuss with the group, in addition to the regular course reading. The presenters were asked specifically to relate the papers' content to their teaching experience. Relations to past experience and current practice were at the focus of all course assignments and discussions. Course B topics were biology understanding and misconceptions, central biological ideas, and inquiry teaching and learning, while "Learning for understanding" served as an organizing theme throughout the course (Table 2). The personal section of all the assignments included a requirement to ask questions. The authors were the developers and instructors of this course.

It is important to note that both courses fostered an atmosphere of sharing all participants' practical knowledge and mutual contributions based on their rich teaching experience.

During the second semester of the 2010-2011 academic year, course B teachers studied a science education theoretical course (course $C$ ). This course was designed as a traditional lecture-based course and included ten reading assignments that were mostly unrelated to the teachers' practice. Course $\mathrm{C}$ participants also included teachers of chemistry, physics, and mathematics participating in the graduate program. The questions asked by the biology teachers in one reading assignment of course $\mathrm{C}$ were collected.

\section{Data collection}

The participating teachers were invited to ask questions throughout courses $\mathrm{A}$ and $\mathrm{B}$, both during the meetings and online. In each course, they were asked to submit 
Table 1 Course A topics and assignments

\begin{tabular}{|c|c|c|}
\hline Topic & Reading assignment (1) (individual, short) & Planning assignment (3) (small groups, long, individual reflection \\
\hline Goals of biology teaching & - & $\begin{array}{l}\mathrm{A}-\mathrm{P} \mathrm{P}^{\mathrm{b}} \text { : Analyzing the learning goals and teaching strategies in } \\
\text { one of the teachers' learning activities, planning and } \\
\text { explaining changes in the activity and/or goals, and describing } \\
\text { the relations to the biology curriculum goals }\end{array}$ \\
\hline $\begin{array}{l}\text { Promotion of students' interest } \\
\text { in biology using students' } \\
\text { questions }\end{array}$ & $\begin{array}{l}\text { A- } R^{b} \text { : Pre-reading of an article on students' } \\
\text { interests and questions in science teaching } \\
\text { (Baram-Tsabari \& Hagay, 2009) }\end{array}$ & 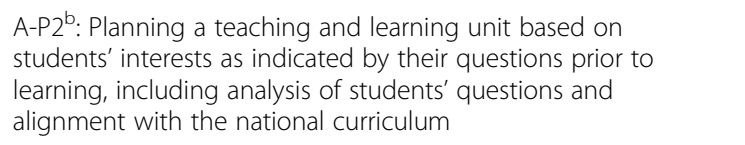 \\
\hline $\begin{array}{l}\text { "Learning for understanding" } \\
\text { (Perkins \& Blythe, 1994) and } \\
\text { formative assessment }\end{array}$ & - & $\begin{array}{l}\text { A-P }{ }^{\text {b: }} \text { Discussion in small groups, and submitting, individually, } \\
\text { one of the following: a. planning a teaching unit according to } \\
\text { the "Learning for understanding" approach (Perkins \& Blythe, } \\
\text { 1994), b. planning and using concept maps as an } \\
\text { understanding performance or formative assessment, c. } \\
\text { analyzing an example of formative assessment used in class in } \\
\text { the "Learning for understanding" framework }\end{array}$ \\
\hline
\end{tabular}

${ }^{\mathrm{a}}$ The number of assignments appears in brackets

${ }^{\mathrm{b}}$ The assignment code: for example A-R means the reading (R) assignment in course A, A-P2 means the second planning (P) assignment in course $A$

three planning group assignments, each designed to enable the teachers to connect theory to practice and vice versa (see Tables 1 and 2). In the final part of each assignment, termed "a bird's-eye view," teachers were requested to respond individually. This part consisted of several reflective and meta-cognitive items, including one inviting the teachers to raise questions, without directing them to a specific topic or track. Thus, those questions were termed self-generated. In the reading assignments of courses A and B, the teachers were asked to specify the main ideas of each article, to describe their reservations and to raise questions, again with no specific direction. In the reading assignment of course $C$, the teachers were asked to read part of Vygotsky's work
(Vygotsky, 1978) and directed to ask questions about the "zone of proximal development." The total number of questions collected was 310: 108 from the assignments of course A, 122 from the assignments of course B, and 80 from the assignment of course $\mathrm{C}$.

\section{Data analysis}

This mixed methods research employed a grounded theory approach (Strauss \& Corbin, 1994), hence the categories emerged from the data in the course of the data analysis.

During the first stage of this research, all of the questions posed by the teachers (teachers-as-learners' questions) in the four assignments of course A $(n=108)$

Table 2 Course B topics and assignments

\begin{tabular}{|c|c|c|}
\hline Topic & Reading assignment (4) (individual, short) & $\begin{array}{l}\text { Planning assignment }(3)^{a} \text { (small groups, long, individual } \\
\text { reflection) }\end{array}$ \\
\hline $\begin{array}{l}\text { "Learning for understanding" } \\
\text { (Perkins \& Blythe, 1994)_first } \\
\text { lesson and organizing theme }\end{array}$ & $\begin{array}{l}\text { B-R1 b: pre-course on "Learning for understanding" } \\
\text { approach (Wiske, 1997) }\end{array}$ & - \\
\hline $\begin{array}{l}\text { Understanding and } \\
\text { misconceptions }\end{array}$ & $\begin{array}{l}\text { B-R2 } 2^{\text {b }} \text { (choose one paper on): cognitive conflict in } \\
\text { biology (Dreyfus \& Jungwirt, 1992), understanding } \\
\text { photosynthesis (Amir, 1993), micro-macro levels and } \\
\text { understanding of genetics (Marbach-Ad, 1998), } \\
\text { analogies to solve micro-macro difficulties } \\
\text { (Dreyfus \& Jungwirt, 1991) }\end{array}$ & $\begin{array}{l}\text { B-P }{ }^{\text {b. }} \text { : Planning a teaching and learning unit }{ }^{3} \text { to better } \\
\text { understand a biological concept or process, using } \\
\text { appropriate strategies and the "Learning for } \\
\text { understanding" framework (Perkins \& Blythe, 1994), } \\
\text { including analysis of misconception type and probable } \\
\text { sources }\end{array}$ \\
\hline Central biological ideas & $\begin{array}{l}\text { B-R3': Applying structure-behavior-function (SBF) } \\
\text { model to biology learning (Liu \& Hmelo-Silver, 2009) }\end{array}$ & $\begin{array}{l}\text { B-P } 2^{\text {b. }} \text { Planning a teaching and learning activity }{ }^{c} \text { to } \\
\text { better understand a biological concept using the SBF } \\
\text { model, and the "Learning for understanding" approach. } \\
\text { Including a description of former ways of teaching the } \\
\text { concept and the SBF components }\end{array}$ \\
\hline $\begin{array}{l}\text { Inquiry teaching and } \\
\text { learning }\end{array}$ & $\begin{array}{l}\text { B-R4 }{ }^{\mathrm{b}} \text { (choose one paper on): students' research } \\
\text { questions and curiosity in inquiry project (Zion \& Sadeh, } \\
\text { 2007), teachers experiencing open inquiry (Sheinin \& } \\
\text { Zion, 2010), history of inquiry and present situation in } \\
\text { schools (Dvir, 2000), teaching biology as inquiry (Ofrat, } \\
\text { 2002) }\end{array}$ & $\begin{array}{l}\text { B-A } 3^{\text {b: }} \text { Analyzing the levels of inquiry in one of the } \\
\text { teachers' learning activities (Table } 2.6 \text { in Olson \& Loucks- } \\
\text { Horsley, 2000), planning to increase the degree of } \\
\text { inquiry openness and to incorporate the "Learning for } \\
\text { understanding" approach (Perkins \& Blythe, 1994) }\end{array}$ \\
\hline
\end{tabular}

${ }^{\mathrm{a}}$ The number of assignments appears in brackets

${ }^{\mathrm{b}}$ The assignment code: for example, B-R4 means the fourth reading (R) assignment of course $\mathrm{B}$

'Learning unit consists of elaborate plan of 1-3 lessons including all activities, while the learning activity is usually a part of a lesson 
were collected and read thoroughly and repeatedly. Initial categories regarding theory and practice were established, which were then refined by several cycles of analysis (following Patton, 2002). Although we were aware of individual differences between the participating teachers, we chose to analyze their questions as a cohort. This framework could be applied to most of the questions asked in the course A assignments; five questions addressed biological content rather than education or science education content and were therefore omitted.

Reliability was obtained using a blinded categorization of 15 questions by two other researchers. The initial agreement rate with each of the researchers was $74 \%$. Following discussion, the final agreement rate was $93 \%$.

The second stage of the research involved collection and analysis of new questions from the seven assignments of course B $(n=122)$ and from the single reading assignment of course $C(n=80)$ using the framework developed in the first stage (see Table 3). Two questions were omitted from this pool as they were articulated very generally and were not clear enough. Reliability was obtained using a blinded categorization of 13 questions by the two other researchers mentioned above. The agreement rate between raters was $85 \%$. Two different comparisons were used for answering the first research question (see "Findings"). Due to the relatively small number of teachers participating in the courses and in the research, Wilcoxon non-parametric test was used for statistical analysis of the data for the first research question. The variables were the categories presented in Table 3.

Two additional means of analysis, which revealed information about the content of the teachers' thinking from the questions, were used in order to answer the second research question. Those means focused on the two categories of questions connecting teachers' practice with the theory learned in the courses. One form of analysis revealed the types of connections that the teachers were thinking about while asking the "practice and theory" questions. Each question was analyzed to uncover the connection type. For example: How do I move to more guided and less structured inquiry? was interpreted as the teacher asking about possible application of the theory (on levels of inquiry) to her practice. This type of question was labeled as "contribution." All of the "practice and theory" questions were analyzed in this manner and then grouped into the two categories of connections emerging between practice and theory.

Another type of analysis focused on the practical aspects of the teachers' questions categorized into the two categories: "practice and theory" and "practice vs. theory." Since the theory was introduced during the course, it was informative to reveal the main aspects of practice being considered by the teachers while thinking about the connections to the theory they had just been exposed to. All of the questions of the "practice and theory" and "practice vs. theory" categories were read repeatedly and given an initial "practical aspect" description, which was then refined by several cycles of analysis to the final categories presented in the findings section.

\section{Results}

As already noted, this research had two objectives. The first was to explore the contribution of a supportive course pedagogy to the connections formed by the teachers between theory and practice, using teachers-aslearners' questions asked in the context of academic courses for experienced biology teachers. The second was to characterize the connections made by the teachers between theory and practice and the practical aspects of their thinking during academic courses as expressed in their teachers-as-learners' questions. The findings are arranged according to these two objectives.

\section{A supportive course pedagogy contributed to the formation of connections between theory and practice by the teachers}

The teachers' questions were analyzed according to the emergent framework presented in Table 3. Our analysis yielded four distinct categories of teachers-as-learners' questions: (i) practice, which focuses on acts and behaviors in class with no relation to theory; (ii) theory, which focuses solely on the theory, with no relation to practice;

Table 3 The practice-theory framework of teachers-as-learners' questions

\begin{tabular}{lll}
\hline Category & Description & Example $^{\text {a }}$ \\
\hline Practice & $\begin{array}{l}\text { Focus on acts and behaviors in class, not } \\
\text { relating to theory }\end{array}$ & How can one increase the level of interest in class? \\
Theory & $\begin{array}{l}\text { Focus on theory, without any relation to } \\
\text { practice }\end{array}$ & Is there a connection between question-asking and academic achievements? \\
$\begin{array}{l}\text { Practice and } \\
\text { theory }\end{array}$ & $\begin{array}{l}\text { Connecting theory and teachers'/students' } \\
\text { Practice vs. }\end{array}$ & $\begin{array}{l}\text { Good questions are based on knowledge. What happens when the student does not } \\
\text { theory }\end{array}$ \\
\hline
\end{tabular}

${ }^{a}$ All examples were taken from the second planning assignment that dealt with students' questions as a means of increasing their interest in biology 
(iii) practice and theory, which attempts to connect theory with teachers'/students' acts; and (iv) practice vs. theory, which attempts to confront the teachers' practical knowledge with the educational theory learned. The "practice vs. theory" category is clearly a subcategory of the "practice and theory" category, but was treated as distinct due to an apparent difference in the various teachers' standpoints: their attempts to know more or understand better ("practice and theory") as opposed to expressing critical thinking about the theory ("practice vs. theory").

Our findings concerning the first research question were based on these categories (Table 3) and include two sections: first, an inclusive comparison between the questions asked in courses A and B and course C's assignment, then a specific analysis of types of connections with regard to assignment type and context.

\section{Overall course pedagogy supported the formation of connections between theory and practices}

The analysis of all teachers-as-learners' questions according to the practice-theory framework (Table 3) produced a similar distribution in courses A and B (Fig. 1). Using Wilcoxon non-parametric test, there was no significant difference.

Since the teachers' questions were collected in the context of two dissimilar courses, the fact that the various types of questions were similarly distributed is interesting, especially since the questions relating theory and practice (categories "practice and theory" and "practice vs. theory") constituted more than 65\% (course A) and $70 \%$ (course B) of their questions (Fig. 1).

The similarity in rationales and pedagogies of these two courses seems to matter. These results suggest that when the teachers learn in courses that focus on creating a learning atmosphere which mediates science education theory and everyday practice, they tend to focus their thinking on this relation, as reflected in their questions.

The importance of course pedagogy in forming connections between theory and practice can be demonstrated in the analysis of the questions asked by teachers who attended the theoretical science education course (course $\mathrm{C}$ ). In a reading assignment handed out in course C, most (64\%) of the 80 questions asked by the teachers were directed to theory, with no relation to practice. Thus, it seems that while the course framework and pedagogy supported engagement in the connections between theory and practice (courses A and B), the teachers not only directed most of their thinking to this association but addressed almost no questions to theory alone, and only minimally raised practical questions. In contrast, when the course framework and assignment focused solely on theory (course C), most of the teachers' thinking was directed to theory, and not to the connections between theory and practice.

\section{Reading assignments in a practical context supported the formation of positive connections between theory and practices}

To examine whether the differences between the three planning assignments and the reading assignment (see "Methodology") were expressed in the teachers' questions, we grouped course A teachers' questions according to assignment type (planning or reading), as presented in Fig. 2. The overall distribution of the questions in the two types of assignments was quite similar: most of the questions (planning: 65\%, reading: $73 \%$ ) dealt with connections between theory and practice (categories "practice and theory" and "practice vs. theory"). Using Wilcoxon non-parametric test, there was no

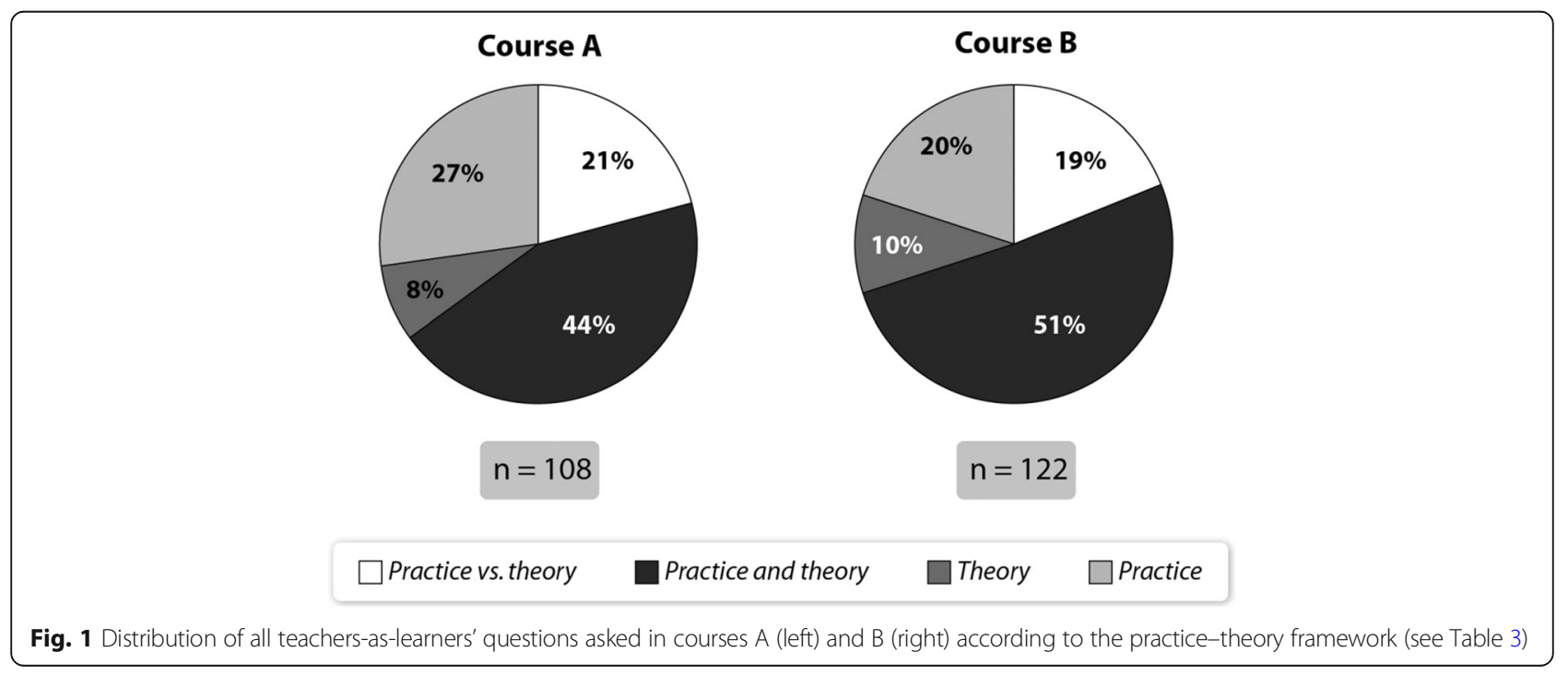


significant difference. Only a few questions dealt solely with theory and about a quarter of the questions addressed exclusively practice (Fig. 2).

Interestingly, the number of "practice and theory" questions asked in the context of the reading assignment was lower than that of questions asked in the context of the planning assignment ( $p<0.05$, Wilcoxon non-parametric). In contrast, the number of "practice and theory" questions asked in the context of the planning assignment was higher ( $p<0.05$, Wilcoxon non-parametric) compared to "practice vs. theory" (Fig. 2). Thus, when theory was presented in the form of an article (the reading assignment) prior to learning the subject, the teachers asked more "practice vs. theory" questions than during the planning assignment. These questions were critical in nature, implying that the teachers tended to notice the gap between the theories that they were reading about in the article and the practical knowledge originating from their everyday experience as biology teachers. When encouraged to narrow the gap between theory and practice by working collaboratively with their colleagues on the planning assignments, which required applying theory to practice, or by analyzing examples of their existing practical knowledge using theory, the teachers asked more "practice and theory" questions, thus indicating their need to better understand the connections between the two.

We planned the 2010-2011 course (course B) with these results in mind. Consequently, we incorporated three reading assignments in the three topics which were chosen as relevant to the teachers' everyday practice and one pre-course reading assignment that was not specific to biology teaching (see "Methods"). The analysis of the questions asked in the two types of assignments (planning and reading) in course B is presented in Fig. 3.

About half of the questions asked by the teachers who participated in course B were directed to connecting practice and theory. Using Wilcoxon non-parametric test, there were no significant differences between the two types of assignments, i.e., planning and reading. The teachers asked more questions confronting theory with practice in the reading assignments than in the three planning assignments, but less than those asked by the participants of course A ( $25 \%$ and $40 \%$, respectively, see Fig. 2). This indicates that the incorporation of reading assignments in the context of teachers' experience and everyday work may enable the teachers to think about the practice-theory connections more positively. They were more engaged in understanding the relevance and contribution of science education theory to their teaching and less in thinking of the differences between their practice and the learned theory. This interpretation is supported by the distinction between the first reading assignment, which was given as a pre-course assignment, and the other three reading assignments, which were given in a learning context emphasizing the connections between practice and theory. Fifty percent (12/24) of the questions asked in the pre-course reading assignment confronted theory with the teachers' practice, whereas only $12 \%(5 / 43)$ of the questions confronted theory with practice in all three incorporated reading assignments. Moreover, most of the questions asked in the context of these three integrated reading assignments (53\%) were classified in the "practice and theory" category.

To sum up, most of the teachers' questions asked under a supportive pedagogical design were directed to the connection between practice and theory. In particular, incorporating reading assignments in a practical context supported teachers positively connecting their practice and theory.

Types of connections formed by teachers between theory and practice, and the practical aspects of these connections

The teachers who participated in this study were invited to ask questions during assignments that were designed to promote the connection between practice

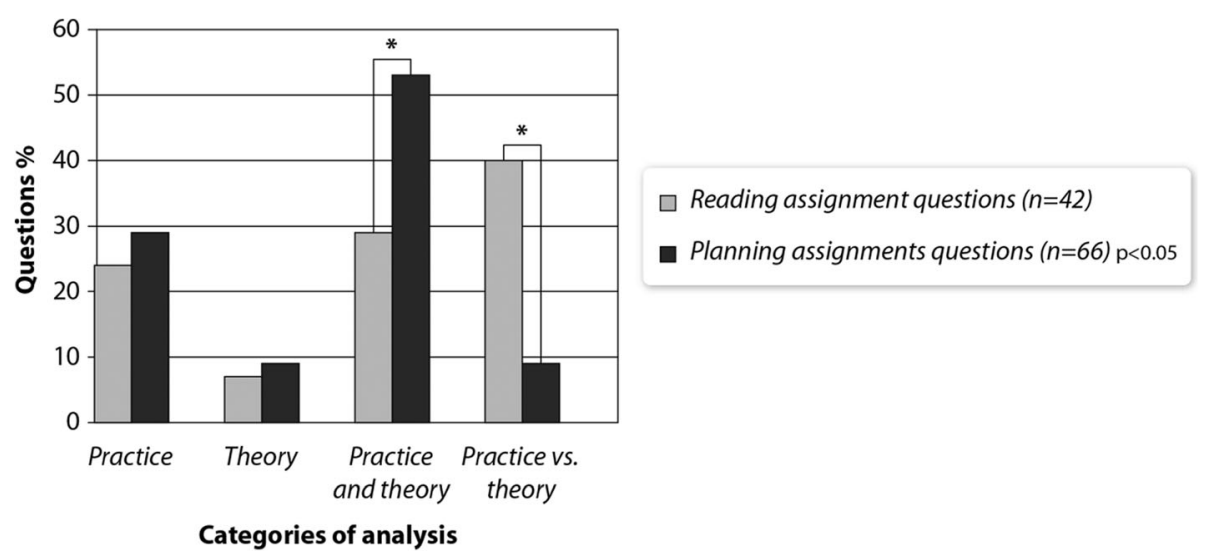

Fig. 2 Distribution of teachers-as-learners' questions regarding practice and theory in two types of assignments in course A (2009-2010) 


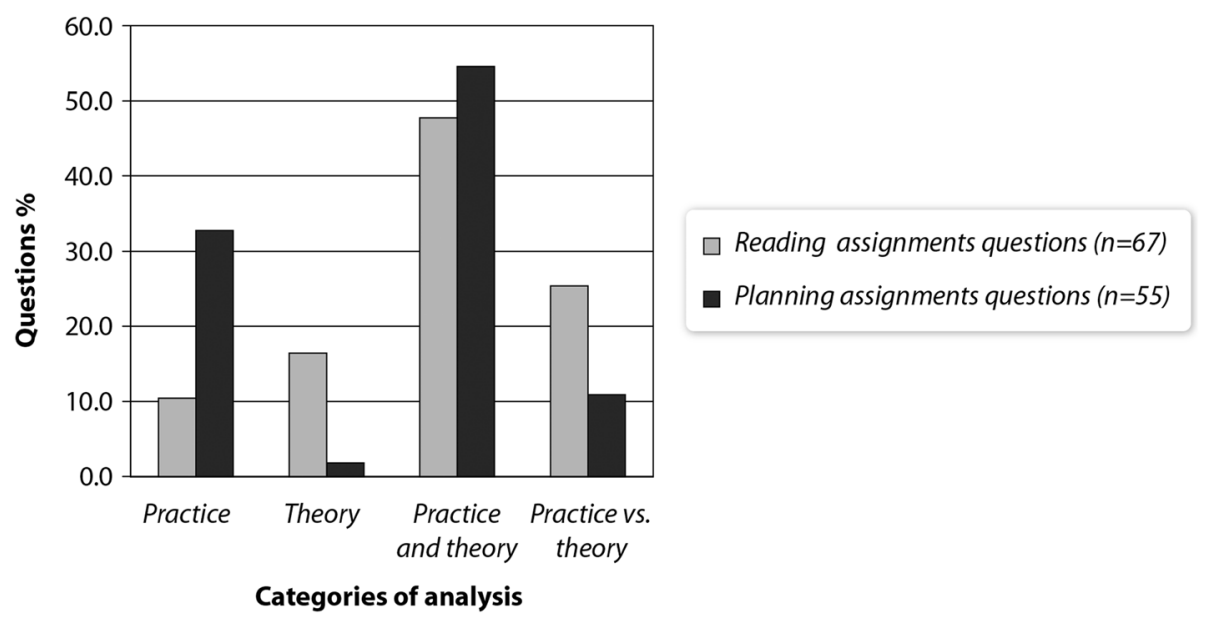

Fig. 3 Distribution of teachers-as-learners' questions regarding practice and theory in two types of assignments in course B (2010-2011)

and theory. The teachers were mostly thinking of the possible contribution of the theory they learned to their practice while asking questions associating the two. While trying to connect or confront their practice with the theory learned in the course, the teachers raised questions regarding different aspects of their work. They were thinking about the ways in which they plan and teach in most cases, and about their students' learning and diversity. They were also expressing the influence of the educational system on their work.

Teachers' questions were classified according to two different attributes: the types of connections formed by the teachers between practice and theory, and the practical aspects of questions connecting theory and practice.

\section{Types of connections formed by teachers between practice and theory}

A closer look at the contents of the questions classified in the "practice and theory" category revealed two main types of teachers' approaches to the connections between practice and theory:

1. Contribution: How does theory contribute to the teachers' practice or apply to their practice? This type of connection encompassed $77 \%$ of the "practice and theory" category.

For example: After reading a paper about students' misconceptions regarding photosynthesis (Amir, 1993), Teacher K (course B) asked: "How can I deal with the knowledge I have acquired about misconceptions in class?" Following a planning assignment, Teacher Hn (course A) asked: "Probably not every student can deal with every understanding performance-Should we match different understanding performances with different students?" In these examples, the teachers were clearly considering the potential contribution of the theory they had learned in the course to their teaching.

Some of the contribution questions (8\%) dealt with application of the theory to a specific context of the teachers' work. These questions could be generalized as follows: Can the theory be applied to all practical contexts or only to a particular context? For example, while involved in a planning assignment in the inquiry unit, Teacher Sh (course B) asked: "Can the students [low achievers] perform a less structured inquiry?"

2. Confirmation: Does the practice confirm the theory? This type of connection encompassed 23\% of the "practice and theory" category.

For example: in her reflective section of a planning assignment following a unit about understanding and misconceptions, Teacher RB (course B) asked: "Do I teach toward remembering facts, without allowing to think deeply and creating a deep understanding of the topic?" The analysis of all of the questions that focused on the possible connections between practice and theory revealed that the teachers had attempted to connect their own practice to the theory they had just learned by asking mainly about the contribution and application of the theory to their practice in class. Thus, the confirmation category enabled revealing another way of thinking that is critical and reflective in nature. In the confirmation questions, the teachers focused on their students and ways of teaching, wondering about the match to the theory they had just learned.

\section{Practical aspects of the questions relating theory with practice}

The questions targeted at connecting practice and theory (categories "practice and theory" and "practice vs. 
theory") naturally included some aspects of the teachers' practice. Looking at these questions from the practical perspective revealed teachers' main concerns in their everyday work. We identified six practical aspects in these questions which were classified into three categories: teaching, students, and the educational system.

\section{Teaching}

a. Strategies (37\%): Questions addressing ways, methods, and tools for instruction (including assessment). For example: "How can I upgrade the level of inquiry in my learning activities?" (Teacher $\mathrm{RB}$, course $\mathrm{B})$.

b. Planning (20\%): Questions dealing with planning of a lesson, a subject, or an activity. For example: "How can I predict students' misconceptions and plan my instruction accordingly?" (Teacher $\mathrm{O}$, course B).

\section{Students}

a. Learning (14\%): Questions dealing with students' understanding, motivation, and cooperation. For example: 'Do students' questions really reflect their level of interest in the topic?" (Teacher Y, course A).

b. Heterogeneous classes (5\%): Questions considering differences between students. For example: "Is meta-cognitive thinking suitable to all students' levels?" (Teacher O, course B).

\section{The educational system}

a. Limitations (18\%): Questions considering the limitations of the system, such as limited time, curriculum, or the need to prepare the students for matriculation exams. For example: "How can we cover the needed curriculum while basing the instruction on students' questions?" (Teacher S, course A).

b. National planning (6\%): Questions dealing with the national science curriculum and the alignment between different levels of schooling. For example: "Do the curriculum developers take 'learning for understanding' into consideration?" (Teacher C, course B).

Classification of the teachers' questions revealed the teachers' main concerns in our program, and highlighted their complex world. They know, based on their experience, that teaching requires attention to numerous factors, and their questions reflect this knowledge. For example: when theory suggested developing teaching plans according to students' questions (following BaramTsabari \& Hagay, 2009), Teacher H (course A) asked about students' personalities: "Does question-based teaching not damage the learning of shy students who are reluctant to ask questions?" The teacher was clearly associating the theory she had learned with her practical knowledge of students and their difficulties.

\section{Discussion}

The framework developed here to analyze teachers-aslearners' questions (Table 3) shed light on teachers' thinking about theory-practice connections and on the importance of course pedagogy that supports discussion of theory in relation to the teachers' work. Our findings indicated that most of the teachers' questions asked under a supportive pedagogical design were directed to the connection between practice and theory. In particular, incorporating reading assignments in a practical context supported teachers' positively associating their practice with the theory. In contrast, most of the teachers' questions asked during a reading assignment in a theory-focused course were directed solely to theory. Furthermore, the practicing teachers formed two types of connections between practice and theory in their questions: they asked about the theory's contribution to their practice and about possible confirmation of the theory by their practice. While asking questions associating practice and theory, the teachers mentioned practical aspects of their work: teaching strategies and planning, student learning and diversity, the educational system's limitations, and national planning.

The supportive course pedagogy contributed to the formation of positive connections between theory and practice by the biology teachers. One of the major reasons for the theory-practice gap is the teachers' stance on research as not being practical (Broekkamp \& van Hout-Wolters, 2007; Kennedy, 1997). The teachers in our study were given the opportunity to discuss research in the context of their occupation and to work collaboratively on assignments connecting their practice and the theory they had learned. The collaborative work was intended to share their practical experience and deeper their analysis of their practice (Erdas Kartal et al., 2018; Roth et al., 2017). Their questions revealed that they were thinking about practical ways to use the theory in their work. This finding supports other studies showing that certain strategies, such as teachers' research or the use of cases, can help teachers connect theory to their everyday work (van Driel et al., 2001).

In this study, we found that the opportunity to ask questions during assignments that are topic-specific and designed explicitly to combine practice and theory enables teachers to think of both domains and try to better understand their relation. We suggest that this type of 
activity contributes to the accessibility and usability of theory to science teachers, which is frequently claimed to be important for quality instruction (Broekkamp \& van Hout-Wolters, 2007; Kennedy, 1997). As already noted, only a few of the teachers questions addressed only theory. This result shows that the teachers were not interested in theory alone, as suggested in previous research (Kennedy, 1997), thus highlighting teaching as a practical occupation. It appears that from a practitioner's point of view, there is not much interest in theory as such, but rather in the ways in which theory is related to practice. Teachers usually regard research conclusions and theory as distant from their work, and there is therefore a continuing need to assist them in narrowing this gap in order to develop professionally and implement innovations in education. The emphasis given in both courses (courses A and B) on discussing theory in relation to the teachers' actual work and personal experience was reflected in their questions about this association.

Furthermore, we found that the type of assignment is important, as is the context in which the reading assignments are given to the teachers. Assignments which were designed to connect practice and theory and readings that were introduced in relation to the teachers' practice supported teachers' thinking of the association between the two domains: the educational theory discussed in the course and their everyday practice. Hence, both the course pedagogy which encouraged association of practice and theory and the practical context of the assignments can be described as contributing to the teachers' asking more questions directed at the practicetheory connection.

In our study, two types of connections between practice and theory were formed in the teachers' questions: the contribution of theory to their practice and the possible confirmation of the theory by their practice. The teachers also related to the practical aspects of their work: teaching strategies and planning, student learning and diversity, the educational system's limitations, and national planning. Analysis of question content indicated that an invitation to freely ask questions encourages teachers' thinking about theory-practice associations. According to Chin (2004, p. 107): "Self-questioning allows an internal dialogue with oneself, driving the mind to look for patterns and connections, establishing relationships with prior knowledge and building bridges to new perceptions." While asking questions that connected teachers' practice and the theory discussed in the courses, the teachers were mainly attempting to better understand the possible contribution of the theory to their practice or how to apply the theory to their instruction. This finding is not surprising, as teaching essentially involves various actions in class, meaning that most research results or theories are not useful to teachers until the relevant way of action is found and applied.

Teachers' knowledge and practitioners' wisdom are discussed in many works (e.g., Connelly \& Clandinin, 1990; Shulman, 1987). Teachers' concerns about the links between their complex world and educational theory were evident in the questions asked by the participants in this research. The questions content emphasized the teachers' complex practical knowledge. They know, based on their experience, that teaching requires attention to numerous factors. While asking questions connecting practice and theory, the teachers were mainly thinking about strategies of instruction, but also about factors reflecting the realities of schools, such as limitations of the educational system or diversity of their students. These components of teachers' knowledge (Shulman, 1987) seem to be important when teachers are considering a theory's possible contribution to their work.

This study had some limitations. The questions analyzed in this research were collected within the context of our graduate program and courses, and the number of teachers participating in this research was low. Hence, the generalizability of our findings might be questioned. Along the same lines, the group of teachers participating in the graduate program probably does not represent the general population of biology teachers, since they were outstanding experienced teachers selected especially for the program. Nevertheless, we claim that the replication of almost similar results in two courses (A and B) with different topics and participants indicates a trend.

Shulman (2002) concluded that the field of research on teacher education "is in serious need of low-stakes, high-yield instrumentation to monitor the vital signs of teacher development in ways that can guide teacher educators, professional developers, and ultimately teachers themselves" (p. 252). The existing tools for narrowing the theory-practice gap, such as cases or teachers' research (i.e., Korthagen, 2007), are demanding in terms of resources, whereas inviting the teachers to ask questions is very simple and can be incorporated into almost all types of assignments, activities or projects, in long- or short-term learning opportunities. The questions, once analyzed, may be the basis for varied activities, such as teachers' discussions, or teachers' teamwork, to provide solutions associating their practice with the theory. In addition, those questions may serve as indicators of the level of the in-service program theory-practice connection, and contribute to improve it. Teaching is a complex endeavor, and a single tool or method will almost certainly fail to capture its richness. We suggest the use of teachers' questions to assist teachers in bridging the gap between their teaching practice and theory. 
Sustaining teachers seems to be a major problem, and there is therefore a growing need to create spaces that will enable teacher development (Clandinin, 2010). In-service programs that focus on connecting STEM practice and theory and assisting the teachers' thinking about the connections between the two worlds by inviting questions and reflection might serve as a space for teacher growth. Further research is needed to explore the connections between teachers' thinking as manifested in their questions and their actual practice in the classroom.

\section{Conclusions}

This study presents a new framework to probe the ways in which teachers-as-learners view the connections between practice and theory, through their questions, a previously suggested powerful tool to encourage thinking (Chin \& Osborne, 2008). Our findings suggest that self-generated questions (Gross, 2001) are an efficient instrument for teachers to consider various aspects of the connection between practice and theory. In addition, questions became a powerful "window" to the biology teachers' thoughts and concerns. This research also emphasizes the importance of supporting STEM teachers by developing courses and professional development programs that explicitly combine educational theory and practice, since theory alone does not contribute enough to practitioners (Korthagen, 2007).

This research shows that under a supportive design, teachers can associate practice and theory in their questions, which in turn can serve as markers of their thinking. It seems that by addressing most of their questions to both practice and theory, the biology teachers in our research were demonstrating a desire to develop professionally by bringing these two different "worlds" closer together. Based on our study, we call for further investigation of teachers-as-learners' questions as a means of reducing the theory-practice gap. As teacher educators and researchers of STEM education, it is our responsibility to provide new ways of connecting teachers' practice and educational research and theory. Teachers-aslearners' questions hold a promise to contribute to this highly important mission.

\section{Abbreviation}

STEM: Science Technology Engineering and Mathematics

\section{Acknowledgements \\ Not applicable.}

\section{Funding}

This study was supported by a Post-Doctoral Fellowship from the Weizmann Institute of Science, Israel (to YFS).

\section{Availability of data and materials}

The datasets used and/or analyzed during the current study are available from the corresponding author on reasonable request.

\section{Authors' contributions}

YFS developed the academic courses, analyzed and interpreted the data, and was a major contributor in writing the manuscript, as part of her postdoctoral studies at the Feinberg Graduate School of the Weizmann Institute of Science under the supervision of AY. AY collaborated with YFS in the conceptualization of the study, in designing the analysis rubric, and in writing the manuscript. Both authors read and approved the final manuscript.

\section{Authors' information}

Yael Furman Shaharabani, PhD, is currently Head of the Department of Teaching and General Studies, Ort Braude College, Israel.

Anat Yarden, PhD, is a Professor of Science Education, Head of the

Department, and Head of the Biology group at the Department of Science

Teaching,Weizmann Institute of Science, Israel.

Competing interests

The authors declare that they have no competing interests.

\section{Publisher's Note}

Springer Nature remains neutral with regard to jurisdictional claims in published maps and institutional affiliations.

\section{Author details}

'Department of Teaching and General Studies, ORT Braude College, Karmiel, Israel. ${ }^{2}$ Department of Science Teaching, Weizmann Institute of Science, P.O Box 26, 76100 Rehovot, Israel.

Received: 29 September 2018 Accepted: 26 May 2019

Published online: 20 June 2019

\section{References}

Allen, J. M. (2009). Valuing practice over theory: How beginning teachers reorient their practice in the transition from the university to the workplace. Teaching and Teacher Education, 25(5), 647-654.

Amir, R. (1993). Problems of high school students with photosynthesis learning and understanding and analysis of ways of correcting classroom instruction. Biology Teachers Journal, 133, 61-74 (in Hebrew).

Baram-Tsabari, A., \& Hagay, G. (2009). The importance of interest in science education. MOTAV Now, 4, 35-40 (in Hebrew).

Baram-Tsabari, A., Sethi, R. J., Bry, L., \& Yarden, A. (2006). Using questions sent to an ask-a-scientist site to identify children's interests in science. Science Education, 90(6), 1050-1072.

Baram-Tsabari, A., \& Yarden, A. (2009). Identifying meta-clusters of students' interest in science and their change with age. Journal of Research in Science Teaching, 46(9), 999-1022.

Bell, B., \& Gilbert, J. (1996). Teacher development: A model from science education. London: Falmer Press.

Biddulph, F., Symington, D., \& Osborne, J. (1986). The place of children's questions in primary science education. Research in Science \& Technological Education, 4(1), 77-88.

Broekkamp, H., \& van Hout-Wolters, B. (2007). The gap between educational research and practice: A literature review, symposium, and questionnaire. Educational Research and Evaluation, 13(3), 203-220.

Capobianco, B. M., \& Feldman, A. (2006). Promoting quality for teacher action research: Lessons learned from science teachers' action research. Educational Action Research, 14(4), 497-512.

Chin, C. (2004). Students' questions: Fostering a culture of inquisitiveness in science classrooms. School Science Review, 86(314), 107-112

Chin, C. (2007). Teacher questioning in science classrooms: Approaches that stimulate productive thinking. Journal of Research in Science Teaching, 44(6), 815-843.

Chin, C., \& Osborne, J. (2008). Students' questions: A potential resource for teaching and learning science. Studies in Science Education, 44(1), 1-39.

Clandinin, D. J. (2010). Sustaining teachers in teaching. Teachers and Teaching, 16(3), 281-283.

Connelly, F. M., \& Clandinin, D. J. (1990). Stories of experience and narrative inquiry. Educational Researcher, 19(5), 2-14.

De Corte, E. (2000). Marrying theory building and the improvement of school practice: A permanent challenge for instructional psychology. Learning and Instruction, 10(3), 249-266. 
Dori, Y. J., \& Herscovitz, O. (1999). Question posing capability as an alternative evaluation method: Analysis of an environmental case study. Journal of Research in Science Teaching, 36(4), 411-430.

Dreyfus, A., \& Jungwirt, E. (1991). Micro, macro, analogies and other problems in 9th grade biology teaching. Biology Teachers Journal, 129, 1-15 (in Hebrew).

Dreyfus, A., \& Jungwirt, E. (1992). Conflict cognitive strategy as a means to student conceptions change: Implications, difficulties and problems. Biology Teachers Journal, 130, 10-28 (in Hebrew).

Dvir, M. (2000). Instruction of inquiry skills in science-Insight or "cookbook". Eureka, 12, 14-19 (in Hebrew).

Eilam, B., \& Poyas, Y. (2009). Learning to teach: Enhancing pre-service teachers' awareness of the complexity of teaching-learning processes. Teachers and Teaching, 15(1), 87-107.

Erdas Kartal, E., Cobern, W. W., Dogan, N., Irez, S., Cakmakci, G., \& Yalaki, Y. (2018). Improving science teachers' nature of science views through an innovative continuing professional development program. International Journal of STEM Education, 5(1), 30.

Freeman, S., Eddy, S. L., McDonough, M., Smith, M. K., Okoroafor, N., Jordt, H., \& Wenderoth, M. P. (2014). Active learning increases student performance in science, engineering, and mathematics. Proceedings of the National Academy of Sciences, 111(23), 8410-8415.

Galloway, C. G., \& Mickelson, N. I. (1973). Improving teachers' questions. The Elementary School Journal, 74(3), 145-148.

Gross, M. (2001). Imposed information seeking in public libraries and school library media centres: A common behaviour? Information Research, 6(2) Available at: http://InformationR.net/ir/6-2/paper100.html.

Hagay, G., \& Baram-Tsabari, A. (2011). A shadow curriculum: Incorporating students' interests into the formal biology curriculum. Research in Science Education, 41(5), 611-634.

Halai, N. (2012). Developing understanding of innovative strategies of teaching science through action research: A qualitative meta-synthesis from Pakistan. International Journal of Science and Mathematics Education, 10(2), 387-415

Hinton, C., \& Fischer, K. W. (2008). Research schools: Grounding research in educational practice. Mind, Brain and Education, 2(4), 157-160.

Kennedy, M. M. (1997). The connection between research and practice. Educational Researcher, 26(7), 4-12.

Kober, N. (2015). Reaching students: What research says about effective instruction in undergraduate science and engineering. Washington, DC: National Academies Press.

Koc, Y., Peker, D., \& Osmanoglu, A. (2009). Supporting teacher professional development through online video case study discussions: An assemblage of preservice and inservice teachers and the case teacher. Teaching and Teacher Education, 25(8), 1158-1168.

Korthagen, F. A. (2007). The gap between research and practice revisited. Educational Research and Evaluation, 13(3), 303-310.

Korthagen, F. A., Loughran, J. J., \& Russell, T. (2006). Developing fundamental principles for teacher education programs and practices. Teaching and Teacher Education, 22(8), 1020-1041.

Liu, L., \& Hmelo-Silver, E. (2009). Promoting complex systems learning through the use of conceptual representations in hypermedia. Journal of Research in Science Teaching, 46(9), 1023-1040.

Marbach-Ad, G. (1998). How do students explain macro level genetic phenomena by micro level terms? In R. Stavi \& D. Tirosh (Eds.), Theory and practice in mathematics, science and technology education (pp. 89-107). Ramot: Tel-Aviv (in Hebrew).

Nuthall, G. (2004). Relating classroom teaching to student learning: A critical analysis of why research has failed to bridge the theory-practice gap. Harvard Educational Review, 74(3), 273-306.

Ofrat, N. (2002). Teaching biology as inquiry: Difficulties, complexity, emphasis and teacher involvement (pp. 1-18). Jerusalem: Ministry of Education (in Hebrew).

Olson, S., \& Loucks-Horsley, S. (2000). Inquiry and the National Science Education Standards: A guide for teaching and learning. Wahington, DC: National Academies Press.

Patton, M. Q. (2002). Qualitative research \& evaluation methods (3rd ed.). Thousand Oaks: Sage.

Perkins, D., \& Blythe, T. (1994). Putting understanding up front. Educational Leadership, 51(5), 4-7.

Rosenshine, B., Meisler, C., \& Chapman, S. (1996). Teaching students to generate questions: A review of the intervention studies. Review of Educational Research, 66(2), 181-221.
Roth, K. J. (2007). Science teachers as researchers. In S. K. Abell \& N. G. Lederman (Eds.), Handbook of research on science education (pp. 1205-1259). Mahwah: Lawrence Erlbaum Associates.

Roth, K. J., Bintz, J., Wickler, N. I. Z., Hvidsten, C., Taylor, J., Beardsley, P. M., \& Wilson, C. D. (2017). Design principles for effective video-based professional development. International Journal of STEM Education, 4(1), 31.

Roth, W. M. (1996). Teacher questioning in an open-inquiry learning environment: Interactions of context, content, and student responses. Journal of Research in Science Teaching, 33(7), 709-736.

Schon, D. (1983). The reflective practitioner: How professionals think in action. New York: Basic Books.

Sheinin, A., \& Zion, M. (2010). Teachers experiencing open and dynamic inquiry. Biology Teachers Journal, 181, 1-13 (in Hebrew).

Shulman, L. (1987). Knowledge and teaching: Foundations of the new reform. Harvard Educational Review, 57(1), 1-22.

Shulman, L. S. (2002). Truth and consequences? Inquiry and policy in research on teacher education. Journal of Teacher Education, 53(3), 248-253.

Strauss, A., \& Corbin, J. (1994). Grounded theory methodology: An overview. In N. K. Denzin \& Y. S. Lincoln (Eds.), Handbook of qualitative research (pp. 273285). Thousand Oaks: Sage.

van Driel, J. H., Beijaard, D., \& Verloop, N. (2001). Professional development and reform in science education: The role of teachers' practical knowledge. Journal of Research in Science Teaching, 38(2), 137-158.

van Zee, E., \& Minstrell, J. (1997). Using questioning to guide student thinking. Journal of the Learning Sciences, 6(2), 227-269.

Vygotsky, L. S. (1978). Mind in society: The development of higher psychological processes. Cambridge: Harvard University Press.

Watts, M., Alsop, S., Gould, G., \& Walsh, A. (1997). Prompting teachers' constructive reflection: pupils' questions as critical incidents. International Journal of Science Education, 19(9), 1025-1037.

Watts, M., Gould, G., \& Alsop, S. (1997). Questions of understanding: Categorising pupils' questions in science. School Science Review, 79(286), 57-63.

Wiske, M. S. (1997). What is teaching for understanding? Thinking Education, 10, 15-24 (in Hebrew).

Yip, D. Y. (2004). Questioning skills for conceptual change in science instruction. Journal of Biological Education, 38(2), 76-83.

Zion, M., \& Sadeh, I. (2007). Curiosity and open inquiry learning. Journal of Biological Education, 41(4), 162-168 (Hebrew version).

\section{Submit your manuscript to a SpringerOpen ${ }^{\odot}$ journal and benefit from:}

- Convenient online submission

- Rigorous peer review

- Open access: articles freely available online

- High visibility within the field

- Retaining the copyright to your article

Submit your next manuscript at $\boldsymbol{\nabla}$ springeropen.com 